\title{
Hanseníase, exclusão e preconceito: histórias de vida de mulheres em Santa Catarina
}

\author{
Hansen's disease, exclusion and prejudice: \\ life histories of women at Santa Catarina State
}

Patrícia Vieira $\mathrm{M}_{\text {artins }}{ }^{1}$

Sandra Caponi ${ }^{2}$

\footnotetext{
${ }^{1}$ Programa de Pós-

Graduação em Saúde

Coletiva, U niversidade

Federal da Bahia.

Rua Basílio da Gamas/n,

Canela. 40110-040

Salvador BA.

patriciavmartins01@

yahoo.com.br

${ }^{2}$ Programa de Pós-

Graduação em Saúde

Pública, Universidade

Federal deSanta Catarina.
}

Abstract This article describes historical notes about leprosy, from the discovery of the bacillus to the treatment done today. In this text we try to analyzethe perception of somewomen, former leprosy patients, residents of Santa Teresa Hospital, located in the city of São Pedro de Alcântara, Santa Catarina State, on the stigma, prejudice and exclusion they suffered and still suffer today. We used the oral history of three women for research purposes and we found as a result of this "excluding" treatment over the years, that it built some kind of rejection about the disease. The search and affirmation of the identity of the stigmatized subject has become a constant. The model of social acceptance and the fact of being recognized as different and not discriminated is the main issue. Key words Hansenosis, Leprosy, Exclusion, Stigma, I solation
Resumo Este artigo consta de notas históricas sobre a hanseníase, desde a descoberta do bacilo até 0 tratamento realizado nos dias atuais. Busca analisar a percepção de algumas mulheres, ex-pacientes dehanseníase, moradoras do H ospital Santa Teresa, localizado em São Pedro deAlcântara, Santa Catarina, sobre o estigma, preconceito e exclusão que elas sofreram e ainda sofrem nos dias atuais. Utilizamos a história oral de três mulheres para a realização dessa pesquisa e constatamos como a consequência deste tratamento "excludente" ao longo dosanos construiu um certo repúdio em torno da doença. A busca ea afirmação da identidadedo sujeito estigmatizado tornou-se uma constante. 0 modelo de acei tação social almejado e o fato de ser reconhecido como diferente e não discriminado é a grande questão.

Palavras-chave Hanseníase, Lepra, Exclusão, Estigma, I solamento 
Introdução

Este artigo apresenta o problema de algumas mulheres que tiveram hanseníase sob o ponto de vista das representações de ex-pacientes e da relação que elas tiveram com os serviços de saúde pública, bem como sua exclusão do contato diário com familiares e amigos.

A palavra "lepra", que significa escamoso, em grego, era utilizada desde os escritos da Bíblia para designar uma gama de dermatoses, entre elas a psoríase e o eczemaํ. Com o esclarecimento e diferenciação das diversas dermatoses incluídas nesta designação e também pelo fato das palavras lepra e leproso terem adquirido uma conotação de "impureza", sua denominação foi substituída por hanseníase ${ }^{1}$. Tal nome foi em homenagem a Gerhard Amauer H ansen, médico norueguês que, em 1873, descobriu seu agente etiológico, M ycobacterium leprae, também conhecido como bacilo de $\mathrm{H}$ ansen ${ }^{1}$.

Atualmente, a maioria dos casos de hanseníase concentra-se nos países em desenvolvimento da América Latina, Ásia e África. Estima-se que cinco países - Índia, Brasil, Indonésia, M yanmar e Nigéria - contribuem com $82 \%$ de todos os casos de hanseníase registrados no mundo 2 .

O Brasil congrega cerca de $87 \%$ do total de casos de hanseníase em registro nas Américas, apresentando as mais altas taxas de prevalência e incidência desta região, sendo o segundo país do mundo em números de casos. Tal observação pode ser decorrente de maior taxa de diagnóstico e notificação dos casos de hanseníase ou de uma taxa realmente alta de casos.

0 fato de haver alta endemicidade da doença em al gumas áreas do país, de certa forma, obriga os profissionais de saúde, independente da região onde vivam, a estarem prontos para diagnosticar e tratar, o mais imediatamente possível, a doença, bem como a abordarem tais pacientes para que consigam o máximo de aderência ao tratamento, pois esta patologia milenar tem cura e, na dependência do tipo de hanseníase, quando o tratamento é precoce, há possibilidade de cura sem sequela. Entretanto, quando a doença evolui acarretando sequelas, estas são responsáveis pelo estigma sofrido pelo indivíduo. Estepreconceito traz limitações em sua vida, em diversas dimensões.

\section{M etodologia}

A coleta de dados foi realizada através da história oral’3. Buscamos, nessa pesquisa, um levantamento bibliográfico da história da hanseníase ea utilização da história oral para resgatar depoimentos de três ex-pacientes mulheres que tiveram essa doença. Os nomes das entrevistadas foram trocados por três codinomes: Ana, Sandra e Ione, para assim manter o verdadeiro nome em sigilo. Não houve uma seleção de amostras, mas uma seleção de sujeitos a partir de critérios intencionais, que se tornaram suficientes para a exploração dos aspectos relacionados ao objeto de estudo. Conhecendo a história do sujeito, podemos conhecer melhor os significados que estes dão ao processo de adoecimento e suas implicações relacionadas ao estigma decorrente da hanseníase.

A pesquisa foi realizada no Hospital Santa Teresa, local izado em São Pedro deAlcântara (SC). Para a seleção dos sujeitos, foram utilizados os seguintes critérios: ser maior de dezoito anos, ser ex-paciente de hanseníase, estar residindo ou ser ex-morador do hospital, ter tempo para a realização das entrevistas, querer participar da pesquisa, autorizar a publicação dos depoimentos. Porém, querer participar ou não participar desse estudo foi um direito dessas mulheres enão apenas um critério de inclusão ou exclusão.

Esses critérios nos permitem estudar e analisar as informações a serem pesquisadas com mais clareza. 0 tempo de permanência no hospital também entrou como fator investigatório. Momentos de interação são processos de ir-evir constantes, caracterizando-se como movimentos não lineares e interdependentes de coIher, registrar, analisar e devolver os dados de pesquisa ${ }^{4}$.

\section{Discussão eresultados}

$$
\text { O hospital }
$$

A Colônia Santa Teresa foi inaugurada em 10 de março de 1940. Essa instituição foi criada para amparar "material e moralmente" os hansenianos de Santa Catarina e está situada no município de São Pedro de Alcântara, a 29 quilômetros de Florianópolis 5 . Possui um território de 2.099.803 metros quadrados, sendo 200 mil metros de área construída, foi edificada em terreno plano, circundada de morros, alguns apropriadosà agricultura, e do rio I maruim. Os primeiros pacientes a serem abrigados nesseestabelecimento chegaram em 25 de março desse mesmo ano, quinze dias após a inauguração. 0 número total era de 441 indivíduos, distribuídos em 221 homens, 194 mulheres e 26 crianças. Os pacientes 
eram encaminhados de forma compulsória, ou seja, internamento obrigatório e de isolamento ${ }^{5}$.

Os pacientes, na Colônia Santa Teresa, eram registrados no "Livro de Registros de Entrada", onde constavam os principais dados de cada indivíduo, tais como nome, data de nascimento, cidade, "raça", data de entrada, etc. Posteriormente, foram criadas as Fichas Sociais e de Assentamento, onde eram registrados dados mais detaIhados de cada interno ${ }^{5}$.

A arquitetura local apresentava uma distribuição bastante particular, sendo sua estrutura planejada para dar aos residentes uma vida similar à que poderiam ter fora da Colônia. 0 local foi construído para parecer uma autêntica cidade, com ruas, casas, cemitério, moeda interna, delegacia, prefeitura, igreja, teatro e cassino. As construções eram dividas em três "zonas": A, B e C. A zona A, considerada "sadia", contava com a residência do diretor, residência do administrador, usina termoelétrica, captação d'água, caixa d'água e casa do médico (em construção). A zona B, considerada "intermediária", contava com a portaria no limite das duas áreas, pavilhão da administração, residência das irmãs, residência do capelão, pavilhão de observação, lavanderia, entrada do pavilhão dos serviços médicos, aviário e cozinha. A zona C, considerada "doente", contava com pavilhão de recepção, pavilhão $\mathrm{Er}$ nani Agrícola, sete casas residenciais para funcionários, quatro casas residenciais para mulheres, um pavilhão infantil, nove grupos de casas geminianas, pavilhão de serviços sociais, capela em construção, gruta de Lourdes (construída pelos doentes), praça de esportes, forno de incineração, fossa, aviário, cemitério, engenho de farinha e torrefação de café, pocilga, olaria movida à tração animal, casa de madeira onde funcionava provisoriamentea marcenaria, uma casa servindo de escola e o pavilhão para psicopatase delinquentes 5 . $\mathrm{H}$ avia ainda projetos para a construção do pavilhão de isolamento, pavilhão de inválidos, pavilhão da prefeitura, pavilhão da escola, pavilhão da oficina e quatro grupos de casas geminadas 5 .

Na Colônia Santa Teresa (pavilhão de administração), funcionava uma agência dos Correios e quando os internos escreviam cartas para seus familiares e amigos, antes de serem enviadas a estes, elas eram desinfetadas, pois acreditava-se que a transmissão poderia ocorrer por meio desse processo. Também foram criados outros órgãos: cartório e cadeia. 0 cartório fez-se necessário para registro de nascimento, casamento eóbito dos doentes. A cadeia tinha caráter punitivo para os doentes que ousassem ultrapassar os limites de sua zona residente ${ }^{5}$.

Cinco anos após sua inauguração, a Colônia Santa Teresa abrigava quinhentos enfermos ${ }^{5}$.

Nos dias atuais, 43 ex-portadores de hanseníase, com sequelas físicas, psicológicas e sociais, permanecem no Santa Teresa, ou retornam à instituição, seu lar e refúgio, onde reencontram pessoas que compartilham do mesmo sofrimento e discriminação, que reconhecem e tratam sua dor sem preconceito ou medo de adquirir a doença, medo queainda se instala nas demais instituições do país. Com o passar dos anos, a instituição ainda mantém antigos funcionários públicos trabalhando, bem como os filhos destes, pois eles já conhecem os pacientes-moradores, moram perto e participaram da reestruturação da unidade. Esse tipo de relacionamento contribuiu para manter o HST deportas abertas einstal ar novos serviços eprojetos para justificar à sociedadecatarinense os recursos públicos que lhe são destinados.

\section{Estigma e depoimentos}

Asmulheresqueforam entrevistadas demonstraram em algunstrechos desses depoimentos que acreditam terem ficado doente por determinações do destino. Elas acreditam que algumas pessoas ficam doentes quando passam a conviver com vícios e maus hábitos de higiene, não tomando conta do seu corpo e sua saúde. Também acham que a doença pode se dar através do meio ambiente e pela insatisfação com a vida.

Temos aqui três histórias de vida: história da Ana, Sandra e lone.

Dona Ana veio para a Colônia Santa Teresa ainda muito jovem, tinha apenas 22 anos. Levava uma vida "normal" com seus familiares e amigos e, de uma hora para outra, foi bruscamente retirada de seu convívio familiar, da sua rotina de vida e enclausurada num hospital que ficava distante da sua casa, sem conhecer ninguém e sem nenhum tipo de assistência psicológica para o horror que se transformaria sua vida, nesse isolamento. Não podia receber visita e depois de algum período nesse local, ela recebe a notícia que seu irmão também iria morar no hospital, porém eram separados por pavilhões. Continuava, assim, seu isolamento e prisão. De certa forma, vivia sozinha.

Dona Sandra também foi internada compulsoriamente no hospital, vindo para cá com dezessete anos. Passou ali muitos anos, onde conheceu seu marido, também ex-paciente do local, e tentou seguir sua vida. Passou al guns anos 
fora do hospital, quando eles não eram mais obrigados a ficar isolados e internos, porém foi acometida de diversas sequelas decorrentes da hanseníase, sendo uma delas o encurtamento dos dedos das mãos que não a permitem ter uma vida sozinha. 0 falecimento do seu marido fez com que ela voltasse a morar no hospital, pois sem filhos ou parentes, ela se via sozinha e sem outra alternativa. Não conseguiu engravidar $\mathrm{e}$ hoje sabemos que isso se deve pela sequela causada pelas drogas na tentativa de curar a doença.

Dona Ione não mora no hospital, apenas reside no período em que está fazendo o tratamento. Ela comenta que a família e os amigos não sentem preconceito em relação a isso; ela é quem quis viver um tempo aqui. Relata preferir ficar nesse período, aproximadamente seis meses, pois tem medo de ter alguma reação causada pelas drogas, ecomo ela mora em outra cidadee não pode ficar selocomovendo, ela fica esse período aqui. Agora, um fator que causou questionamento foi: se a família e os amigos não têm preconceito, por que não recebe nenhuma visita nesse período?

Todas essas mulheres conversaram conosco durante aproximadamente um hora e quarenta minutos e todas elas estiveram dispostas a falar sobre seus medos e seu expectativa em relação ao futuro. 0 que mais impressionou foi a doçura no olhar de cada uma delas; apesar de todo horror que sofreram, conseguiram superar sua dor e são mulheres com um senso de humor indescritível!

Sabemos que o estigma ainda existe, apesar dessas mulheres terem conseguido superá-lo, porém denominava-se estigma todo indicativo pelo qual o indivíduo era diferenciado, seja por um crime, por uma loucura ou uma doença. Os gregos, na antiguidade, usavam a existência desse indicativo para tornar visível qualquer coisa de extraordinário, deruim, sobreo status de uma pessoa ${ }^{6}$. Já na era cristã, utilizava-se o termo estigma para diferenciar pessoas que apresentavam sinais corporais decorrentes de al guma graça divina ou também quando o indivíduo apresentava al gum distúrbio físico ${ }^{6}$. 0 termo estigma semprefoi relacionado ao sentido condenatório, levando o indivíduo à exclusão social, banido por exclusiva "culpa" sua, por ser portador de algum desses indicativos que o comprometessem.

0 termo estigma e seus significados nos faz acreditar que ex-pacientes carregam por muitos anos uma característica distintiva conhecida pela maioria da população e imediatamente percebida por eles: Ah, eu tinha lesões, tinha caroços, né, tinha a pele bem grossa, bem feia, né, depois saiu uma impinge aqui no meu rosto e aquilo ali foi tomando conta. Aqui tudo cheio assim, no tornozelo. Daí eu comecei a passar mal e o médico me mandou pra cá. (Ana)

Eu morava em Bom Sucesso e descobri que estava doentepor causa deuma mancha branca. I sso foi em 1946. Quando eu fui levar meu pai no mé dico que eu descobri que eu estava doente. Eu vim pra cá com dezessete anos e fiquei internada aqui de 1946 a 1963. (Sandra)

Eu não sentia meus joelhos. Eu estava doente há muitos anos já, mas ninguém descobria o que era. Eu descobri queestava doente, com essa doença, há oito anos. Eu sou de Campos N ovos e então me mandaram pra cá. Fizeram o exame de orelha em mim e depois colocaram duas toalhas quentes nas minhas costas e eu não senti nada. (Ione)

A sociedade sempre estabeleceu meios de categorizar as pessoas conforme seus atributos, fossem eles comuns ou diferenciados da população, ou seja, quando um estranho nos é apresentado, logo procuramos categorizá-lo em algum grupo/tribo ${ }^{6}$. Assim ocorria com os pacientes portadores de hanseníase há alguns anos, quando os mesmos eram retirados à força de suas casas, de seus entes queridos e obrigados a permanecer em hospitais de isolamento: Me mandaram pra cá quando eu tinha dezesseteanos. $\mathrm{Na}$ quele tempo, ainda não tinha tratamento. A gente só tomava injeção. Reação eu nunca tive. $N$ aquele tempo, era obrigado a ficar aqui. (Sandra)

Isso aconteceu há mais de cinquenta anos e nos dias atuais ainda temos pacientes em desvantagens, quando os mesmos procuram isolar-se de familiares, amigos e muitas vezes não conseguem se inserir no mercado de trabalho. Usa-se o termo estigma em referência a um atributo depreciativo. Goffman defende a idéia de que existe uma relação especial entre atributo e esteriótipo ${ }^{6}$.

Podemos ainda mencionar três tipos de estigmas diferenciados: (1) os que mostram as abominações relacionados à aparência física (que aqui nos remetem às feridas, manchas e encurtamentos de músculos, tendões e articulações decorrentes da hanseníase), (2) as cul pas de caráter individual ( percebidas como vontade fraca, ou seja, o indivíduo se sente culpado por ser diferente dos demais) e (3) os estigmas "tribais" (que podem ser transmitidos através de linhagem e contaminar por igual todos os membros de uma família) $^{6}$ :

Pesquisadora: Vocêvem junto com a sua irmã!

Ana: Ele ficou apavorado, né, era novinho, mocinho, não sentia nada. 
A minha família ficou lá em Bom Sucesso, só eu quevim pra cá. Fiquei aqui dos dezessete aos 33 anos. Aqui cada quarto tinha quatro camas. De pois que casei, mudou um pouco. (Sandra)

Hoje minha família aceita que eu venha aqui fazer tratamento edepois volte para casa. Eu moro em Campos $N$ ovos e lá o tratamento não é igual aqui. (Ione)

De todos esses três exemplos de estigma, inclusive aqueles maisantigosque os gregos tinham em mente, todos têm a mesma característica social: uma pessoa que poderia ser recebida na sociedade normalmente, mesmo estando doente e seguida de tratamento, é obrigada a se afastar daqueles que encontra pelo caminho, destruindo qualquer possibilidade desse indivíduo chamar a atenção para outros atributos seus ${ }^{6}$. Com isso, fazemos vários tipos de discriminações através das quais, efetivamente, e muitas vezes sem pensar, reduzimos as chances de vida social desse indivíduo.

Criamos uma barreira para afastar essas pessoas com base nas diferenças, usamos termos pejorativos como aleijado, sujo, incurável como fonte de representação sem pensar no seu significado original ${ }^{8}$. Podemos, também, inferir uma série de imperfeições a partir da "imperfeição" original, ou seja, aquele indivíduo com hanseníase deve ser isolado quando realiza suas atividades diárias, por exemplo, quando se trata de alimentação ou contato físico: Elesiam buscar a gente lá, colocava dentro de uma ambulância lá e trazia, né. E em cada ambulância, se a gente pedia algo, como uma água, eles paravam e não deixavam a gente pegar, não deixavam nada, era jogada na ambulância pra gente como se a gente fosse um animal. (Ana)

Depois de lermos esse trecho da entrevista, nos questionamos sobre a relação que 0 indivíduo faz com sua doença, ou seja, parece possível que ele não consiga viver de acordo com o quefoi efetivamente exigido dele, quesimplesmente não possa ser indiferente ao seu "fracasso", que nesse caso é estar doente, ser leproso. Esse indivíduo sente que éum ser humano completamente normal e que nós é que não somos completamente humanos. Ele carrega esse estigma de ser "leproso", mas não se encontra impressionado. Busca entendimento por que é tratado dessa forma, como um criminoso, sendo isolado e mal tratado. Ele pode se questionar em relação aos seus sentimentos e, como qualquer outro indivíduo, merece um destino agradável, ser tratado com respeito eter uma oportunidademais humana de tratamento e convívio com os demais. Não aceita que, por estar doente,, está abaixo de qualquer outro. Questiona-sesobrea vergonha, quesetorna um sentimento central, surgindo relacionada com a doença, tida na época como impura.

Estar próximo de pessoas normais, como a família e amigos, ou agora próximo aos responsáveis pelos serviços do hospital onde se encontrava quando foi isolado, provavelmente reforma a revisão entre autoexigências e ego, questionando-se sobre sua aparência, "seus defeitos". De todas as maneiras, 0 indivíduo luta contra 0 auto-ódio e a autodepreciação ${ }^{6}$. Esses sentimentos surgem quando aquel es que têm relações com os ex-pacientes, ex-internos nos hospitais de isolamento não conseguem dar o respeito ea consideração que os aspectos "não contaminados" de sua identidade social merecem: $D$ aí depois te falar, depois de vir pra cá, a gente entendemelhor. A gente chegou aqui e logo captou tudo, né? D epois eu lembrei que quando eu ajoel hava assim pra rezar eu ficava com duas bolhas no joel ho, duas bolsas deágua. (Ana)

0 indivíduo estigmatizado, em alguns casos, responde tentando corrigir diretamente 0 seu "defeito", ou seja, procura se tratar corretamente tentando evitar sequelas ou sinais físicos da doença. Ondeesse "conserto" épossível, o que ocorre não éadquirir um status de normalidade, desaúde, mas uma transformação do ego: indivíduo que tinha um "defeito" particular e o corrigi.

Ele pode também tentar "corrigir" a sua condição demaneira indireta, dedicando um grande esforço individual a adaptar-se a sua condição de vida atual; ou seja, se esse indivíduo já apresenta alguma sequela decorrente da doença, da hanseníase, ele irá buscar conviver com isso e tentar suavizar essa condição, por exemplo, se apresenta encurtamento nos membros inferiores, usará sapatos adaptados, se apresenta encurtamento nos membros superiores, tentará reverter ou suavizar seus movimentos com cirurgia e fisi oterapia, se apresenta problema ocular, tentará corrigi-lo também com cirurgia e assim por diante. Esse aprendizado faz com que 0 indivíduo reaja em relação a sua sequela ou limitação e conviva o mais natural mentepossível em relação a isso. 0 indivíduo que é estigmatizado por seu "defeito", por estar com hanseníaseeapresentar sequela, poderomper esse "diferencial torturado" e seguir agindo e vivendo o mais perto do cotidiano de qualquer pessoa.

Contudo, devemos acrescentar que existem os que se acham vítimas e não buscam melhorar sua condição, tentando assim obter ganhos secundários relacionados à doença. $\mathrm{Ou}$ até ver as 
privações que sofreu decorrentes da doença como uma "bênção secreta", na qual o sofrimento the ensina mais sobre sua própria vida.

U ma questão que nos chama a atenção ao estudar sobre o estigma, mais especificamente sobre o estigma referente à hanseníase, são as relações entre as pessoas saudáveis e as pessoas que estão em tratamento ou já estão curadas. Buscamos essa questão, essa situação social, na presença física um do outro, seja numa conversa informal ou não. Nesse contato, evidenciamos quando existe o repúdio, o afastamento das pessoas menos esclarecidas sobre 0 assunto, sobre a doença. E esse afastamento, ao contrário do que a maioria das pessoas imaginam, acontece e muito nos dias atuais. São poucos os profissionais de saúde e demais cidadãos que sabem da situação da hanseníase no Brasil.

Esse encontro entre pessoas saudáveis e doentes, ou ex-pacientes, quando acontece de maneira desagradável, faz com que os indivíduos estigmatizados se isolem cada vez mais, tornando-se pessoas desconfiadas, deprimidas, hostis, ansiosas e confusas. Podemos citar uma versão de Sullivan sobre esses sentimentos: Ter consciência da inferioridade significa que a pessoa não pode afastar do pensamento a formulação de uma espécie de sentimento crônico do pior tipo de insegurança que conduz à ansiedade [...] 0 medo de que os outros possam desrespeitá-la por algo que ela exiba significa que ela sempre se senteinsegura em seu contato com os outros [...]".

A visita vinha mas ficava ali naquela cerca, no portão, né. 0 primeiro preconceito mais forte que eu tive foi quando a gente foi na casa dos meus pais. Daí o motorista do ônibus falou: "Vocês não podem embarcar aqui. Não podem, porque vocês são lá do leprosário". Daí a gentedesceu, daí a gente andou até ali na Colônia Santana. (Ana)

Essa sequência na entrevista nos mostra o que acontece realmente quando pessoas saudáveis e doentes ou ex-doentes dehanseníaseseencontram, especialmente quando tentam manter uma conversa etêm a simultaneidade da causa eefeito desse encontro. 0 indivíduo estigmatizado percebe que podesesentir inseguro em relação àmaneira como as pessoas normais/saudáveis o recebem e o identificam ${ }^{5}$. Tem-seuma incerteza de como será classificado pelos demais, em que categoria será inserido, seserá bem aceito e, quando isso acontece, também prevalecea dúvida se as pessoas o estão tratamento bem por pena, zelo ou dó: O ndeeu fui, onde eu morei, não sentia preconceito de ninguém. Lá no Paraná, ninguém sabia, né, lugar estranho, né. No Paraná, ficamos quatro anos. (Ana)
Eu fui embora com 33 anos.Eu e meu marido compramos uma casinha perto do Regional. As pessoas que eu tinha amizade não sentia preconceito não, mas também ninguém sabia da doença, né. (Sandra)

Por mais pânico que o ex-paciente de hanseníase possa ter em relação ao estigma e preconceito decorrentes da doença, muitas vezes surge a sensação de não saber aquilo que os outros estão realmente pensando dele. Muitas vezes, sente-se exposto e sem ter como reagir a olhares dúbios: Às vezes em casa quando ia parente eu ficava escutando eles dizerem assim: "M eu compadre, minha comadre, essa menina tem essa doença, lepra, né?!" (Ana)

As pessoas ficam olhando minha mão, mas não perguntam nada. Pensam queé reumatismo. (Sandra)

0 estigmatizado, nesse caso, sente também seu problema, seu defeito, por el eestar no físico, ser visual, ser percebido sempre que alguém Ihe dirigir o olhar. Sente que estar entre as pessoas normais/saudáveis o expõe friamente à invasão de sua "privacidade". Isso acontece ainda mais na presença de jovens, crianças eidosos, quando expressam uma curiosidade mórbida em relação à doença. Também acontece uma situação desagradável quando os mesmos resolvem oferecer uma ajuda que não é necessária e nem desejada: Ah, eu me tratava sozinha em farmácia e ia em tudo quanto era médico, nunca fui em médico que fosse do mal, né, me tratei muito tempo em casa. Depois aqui em Florianópolis tinha uma mulher que me endireitou, que se trata aqui e pensou que levando no hospital, chegando lá minha madrinha que era uma mulher muito disposta ela começou a conversar com eles, seu Zé Luis, né. Tenho uma sobrinha que é assim assim assim. Pode deixar queeu vou mandar o Dr. M ilton na casa dela e se for. D epois um dia de tarde eu tava em casa e bateram. Eles chegaram dizendo assim: "É aqui que mora a Ana?"

Em al gumas situações, acontece do estigmatizado se retrair ou ser agressivo ao se aproximar das pessoas, dos contatos mistos, pessoas saudáveis/normais epessoas queapresentam algum tipo de deformidade, e pode acabar provocando nos demais um certo desconforto, situações desnecessárias e desagradáveis. Isso normalmente torna qualquer encontro social desse indivíduo estigmatizado muito angustiante. Sabemos que quando os estigmatizados e os normais/saudáveis caminham em situações sociais mistas, elas nem sempre serão suavizadas e livres de embaraços: 0 médico fal ou: "Vou fazer um exame em você 
e amanhã eu vou fazer na família toda. A senhora sabe, você sabe [tinha 22 anos, era pequena, né] que amanhã você vai pra Colônia Santa Teresa?" Daí eu cheguei aqui meio sem escolha. (Ana)

Muito provável que em situações como essas, em que o médico já conhecia o estigma sofrido pelo paciente, ocorram categorizações inadequadas, etanto médico como paciente sintam-se desconfortáveis. Isso não descarta a possibilidade de ocorrer mudanças significativas no decorrer do tratamento e da relação entre ambos. Em muitos casos, os pacientes aprendem a lidar com esse embaraço com mais naturalidade, visto que a frequência desituações desconfortáveistornamse constantes no decorrer do tratamento.

Jáentreosseus, entreos pacientes dehanseníase, podem ocorrer situações em que eles usem sua "desvantagem", estar doente, para se unirem, se organizarem, se confortarem e estabelecerem um vínculo de compaixão em relação ao outro: Cheguei aqui no dia 27 dejulho de 1947. Vim diretamente para o pavilhão, o meu irmão veio direto comigo. Veio junto, veio. Ele tinha dezoito anos. Daí quando chegou no outro dia de manhã, daí a irmã chegou trazendo cobertor, acolchoado. Daí eu pensei: meu D eus do céu! A gentevai ficar o resto da vida aqui, né? Cismei isso na minha cabeça, né, não disse nada pra ninguém, mas pensei se a gente veio para pouco tempo, porque essa quantidade de roupa, né? Daí fiquei, namorei cinco anos. (Ana)

M orei aqui muito tempo. As pessoas procuravam seajudar, atéquem sabia ler, escrever ensinava os outros. Tinha interno que fazia casinhas, participava das construções. Quando eu era solteira, eu ajudava na enfermaria, dava banho nos mais doentes e tudo. A gente ganhava um trocadinho com isso, era pouco, mas era um trocadinho. Depoisque eu casei, meu marido não queria mais. (Sandra)

Todavia, o estigmatizado pode descobrir que os relatos de seus parceiros de sofrimento 0 aborrecem. Que tudo que remeta à lembrança do seu problema seja um dos maiores castigos por se carregar um estigma: M orei a primeira vez dezessete anos, depois eu fui para fora, morei ali fora quarenta anos, as minhas filhas estudaram, se formaram. Cinco filhos nasceram aqui. Fiquei casada 53 anos, três meses e dez dias. Casei no sábado seguintequeia fazer 27 anos. $\mathrm{Na}$ casinha, moramos dezessete anos, aqui, nas casinhas que tem. (Ana)

Eu não tive filho. Não tive porque não era pra ter mesmo. Eu nunca tomei remédio pra evitar. U ma vida sem filho fica uma vida vazia, inútil, sei lá. (Sandra)

N esses estudos sobre pessoas estigmatizadas, há um profundo interesse pelo tipo de vida cole- tiva desses pares. Procuramos saber por que de fato eles se formam e qual a função efetiva disso na vida de cada um deles. 0 que se sabe é que os membros de uma categoria particular de estigma tendem a se reunir em pequenos grupos sujeitos a uma organização. Além disso, fazendo parte desse grupo, fica mais fácil entrar em contato com qualquer outra pessoa que venha a ter o mesmo "problema", "defeito". Se existe um lado positivo nisso tudo, sabe-se então que é o favorecimento dessas relações: Desde quando eu morava aqui no hospital eu cuidava da minha casa sozinha. Depois mudei morei fora eagora voltei a morar aqui porque meu marido morreu e eu não tenho filhos. Tem casos assim que nem o meu, de quem é sozinha, que o hospital aceita de volta. M eus irmãos todos morreram e agora eu também não consigo mais cuidar da minha casa. Você tá vendo minhas mãos, né? Então. E casinha aqui eu não quero não, eu quero morar nesse quarto mesmo porquedaí eu não tenho quelimpar nem nada, tem pessoas que fazem isso. E eu não consigo mais. Tenho muita saudade da minha casa, mas no fundo a gente acaba voltando pra cá. Eu saio pra comprar minhas coisinhas de comer, né, gosto muito de fruta. Eu ganho a pensão do meu marido etambém gosto muito de ler. (Sandra)

Vale relembrar aqui das condições que foram estabelecidas e criadas na Colônia Santa Tereza, como a criação de vários setores dentro do hospital, que mais pareciam uma cidade. Ali se encontravam banco, cartório, casas separadas por pavilhões, distribuição de alimentos, lavanderia, correio, rádio, teatro, etc. para se conseguir um ambiente mais agradável e menos hostil para moradores e servidores públicos que ali permaneciam por longos períodos. Com a criação desses setores dentro do hospital, criavam-se também cargos internos entre os pacientes, delimitando funções que faziam com que a convivência em grupo tornasse mais acessível o contato entre os pares, entre os grupos, entre as "tribos".

Outra função estabelecida pelo estigmatizado, morador desse hospital, era de agir como um "orador", podendo assim ser um representante dos seus ao tentar reivindicar direitos que Ihes eram omitidos ou pouco questionados.

\section{Consideraçõesfinais}

A vida dessas mulheres às vezes se confunde com a história do Hospital Santa Teresa, visto que algumas delas voltaram a residir no mesmo. Muitas lembranças trazem as imagens do passa- 
do, sendo elas al gumas vezes al egres, saudosistas e, em outras, as lembranças dolorosas do tempo de internamento compulsório.

As marcas existentes em cada uma dessas mulheres são marcas que transcendem as cicatrizes e sequelas da doença, mas permanecem referenciadas pelo seu deslocamento tanto familiar como social. M arcas essas ainda existentes devido à desinformação a respeito da hanseníase, sendo indicativo de estigma em um longo período histórico.

A hanseníase ainda é um grave problema de saúde pública no Brasil, fato esse inegável eobtido através das entrevistas realizadas nesse estudo. A vida dessas mulheres foi prejudicada em diversas proporções, acarretando sequelas permanentes. Espera-se que os dados obtidos nesse trabalho tragam mais esclarecimentos, informações e sensibilidade à população de um modo geral.

\section{Colaboradores}

EBSCoelho eLR Maciel participaram igualmente de todas as etapas da elaboração do artigo.

\section{Referências}

1. Veronesi R. Tratado de infectologia. São Paulo: Atheneu; 1996.

2. Souza CS. Liga de combate à hanseníase "Luiz Marino Bechelli". Inserção de um projeto acadêmico na comunidade. U ma ação de educação em saúde. [site da Internet] [acessado 2003 set 15]. Disponível em: http://www.saudebrasilnet.com.br/ premio_2002_arquivo/trabalho67.asp

3. Araújo $\bar{M}$ F, Patrício ZM , Casagrande JL. Qualidade de vida do trabalhador: uma abordagem qualitativa do ser humano através de novos paradigmas. Florianópolis: Ed. do autor; 1999.

4. Bardin L. Análise de conteúdo. Lisboa: Edições 70; 1977.

5. Boletim do SN L 1945; IV(3). [Documento encontrado na biblioteca da Universidade Federal do Rio de Janeiro. Pavilhão São Miguel. Santa Casa, Clínica Dermatológica]

6. Goffman E. Estigma: notas sobre a manipulação da identidade. 4a ed. Rio de Janeiro: Guanabara Koogan; 1988.

Artigo apresentado em 06/11/2008

Aprovado em 28/06/2009

Versão final apresentada em 21/07/2009 